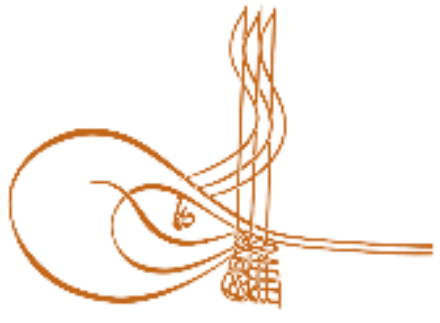

www.turkishstudies.net/social
Turkish Studies - Social Sciences

eISSN: $2667-5617$

Research Article / Araşttrma Makalesi

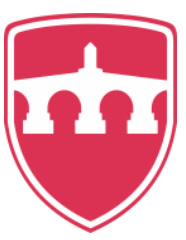

INTERNATIONAL

BALKAN

UNIVERSITY

Sponsored by IBU

\title{
Havalimanı Terminal Perakendeciliği Üzerine Kavramsal Bir Çalışma*
}

\author{
A Conceptual Study on Airport Retailing
}

\author{
Bekir Tuncer** $^{* *}$
}

\begin{abstract}
In this article; beginning in USA in 1978, after the turkey in the liberalization movement in the aviation industry began in 2003, it aims to examine the importance of developing and also gained importance and development of airport retailing. Turkey is also a world tourism and aviation's share of the pie is increasing day by day and also by opening services Airport Istanbul, especially issues that will strengthen the current position to grow even further in the transit market makes it more important. The privatization movements in the aviation sector, which started with airlines, have led to the gradual disappearance of state-owned airlines and the replacement of private airlines. After national and international regulations, ground handling companies, catering services, airport and terminal operations were privatized. As a result of privatization terminal operators have begun to focus on retail revenue in order to increase their total revenues. Although terminal retailing first focused on duty free duty free retailing, the potential of other retail revenues has been recognized in recent years. Since the airports are intense controls in terms of entry and exit, the areas to be retailing are also limited. Since the time from the entrance to the terminal boarding was limited, terminal retailing became an area where more attention should be paid. It is gaining more importance as it is the fastest growing retail sector after e-commerce in global trade. For this purpose, previously conducted studies and findings on airport retailing are compiled, the development of airport retailing, the factors affecting the purchasing behaviour of passengers at the airport are explained, the types of airport retailing are explained and recommendations are provided to the companies operating in this field.
\end{abstract}

Structured Abstract: The liberalization trends of the world has accelerated since 1978 in the aviation industry. Deregulations started in airlines have become widespread in the form of privatization at the airports and terminals of airports. Liberalization movements in the Turkish aviation sector started in 2003. Aviation projects carried out taking into account Turkey's geopolitical advantage have enabled the sector to grow 3 times faster than the world average.

Until the 1960s, airports were built as areas where passengers can get on and off the plane, and with the liberalization movements, they have become the center of shopping, trade and entertainment. In this

\footnotetext{
* Muğla Sitkı Koçman Üniversitesi Bilimsel Araştırma Projeleri Birimince 13/73 numaralı proje kapsamında desteklenen, "Havalimanı Terminal Perakendecilik Hizmetlerinin Satın Alma Davranışına Etkisi: Muğla Dalaman ve Antalya Dış Hatlar Terminal Örneği” isimli doktora tezinden üretilmiştir.

*** * Dr. Öğr. Üyesi Muğla Sıtkı Koçman Üniversitesi, Dalaman Sivil Havacılık Yüksekokulu, Havacıllk Yönetimi Bölümü. Asst. Prof. Dr., Muğla Sitkı Koçman University, Dalaman School of Civil Aviation, Department of Aviation Managemnet. ORCID 0000-0003-0822-6832

btuncer@mu.edu.tr

Cite as/ Atıf: Tuncer, B. (2020). Havalimanı terminal perakendeciliği üzerine kavramsal bir çalışma, Turkish Studies -

Social, 15(3), 1541-1559. https://dx.doi.org/10.29228/TurkishStudies.39551

Received/Geliş: 10 October/Ekim 2019

Accepted/Kabul: 25 April/Nisan 2020

Checked by plagiarism software

Copyright $(C)$ INTAC LTD, Turkey 
context, airport terminals have come to the fore as a means of income diversification. The study aims to present the conceptual literature about the retailing activities carried out at the airport and to make suggestions to the airport terminal retailers. The variety of stores at the airports varies according to the size of the terminal and the passenger structure using the terminal. Retailing activities are carried out in stores belonging to businesses that offer services such as books, mobile phones and accessories, pharmacy, confection, luggage, gift, duty free, restaurant, cafeteria and car rental.

Retailing activities are carried out both on the air side of the airports and on the land side. In terms of airport terminal retailing, the commercial areas located at the car park area and the terminal entrance are considered as land side, and the commercial areas located after the second security check that only passengers can enter are considered as the air side. Most of the retail sales at the airport are on the air side. Passengers are most likely to visit retail locations on the air side as a means of assessing their remaining time after all checks have been completed. The presence of transit passengers using the airport also requires further attention to the retail activities carried out on the air side.

It is observed that after the $1990 \mathrm{~s}$, academic studies on airport retailing intensified. In efforts to increase retail revenues; It is observed that the focus is on the characteristics of the passengers, the store where the purchase is made, whether the purchase behavior is planned, the size of the airport, the adequacy of the retail areas and the time that the passenger entering the airport can evaluate. There are studies that show that passengers' decisions to buy or not, their socio-cultural characteristics, demographic factors, and individual characteristics are effective. The study found that women shop more than men, women's spending is in the form of ready-to-wear, perfumery and books/magazines, while men show more interest in electronic devices.

Research reveals the impact of co-children and friends accompanying passengers on the journey. It has been found that passengers do not tend to buy when they do not think they have enough time. Passengers from countries where a high rate of tax from consumer products; duty-free stores, who prefer to sell, since they spend more young passengers who travel more than one holiday per year, airline passengers flying with a low cost that is more than food and beverage expenditures found in the literature studies that is located. It is also stated by the sector representatives that 65-70 percent of the shopping after the passport control at the airport is instinctive shopping, that is, the shopping that has not been planned before and is decided at the store.

Passengers, also called airport shoppers, often prefer brands that they have previously experienced and known and focus on product diversity. It is useful to carry out the fast and problem-free process from the arrival of the passenger to the airport to the completion of the boarding procedures. Dissatisfaction from security guards can negatively affect perceived service quality and purchasing behavior. In contracts between businesses that carry out retailing activities and the airport terminal operator, the airport operator is usually the owner of the establishment and is generally responsible for the maintenance, lighting, heating and cleaning of the terminal, and tenants are responsible for sales. In return, it collects rent from its tenants in the form of fixed rent, fixed rent + share from revenue or directly from revenue. Sometimes, the terminal operator company can carry out its retailing activities. The general understanding is that retail activities that require a high level of expertise are carried out with specialized retailers in this field.

It will be easy for passengers to have the retail points at the airports on the passenger walkway. The fact that the stores are on the same floor as the boarding gates will help passengers browse the stores more easily while waiting for their flight. Positioning the stores so that passengers can see most stores at the same time at first glance after completing passport and security checks can trigger the passenger's impulse to buy more easily. The personnel of many businesses such as customs, airport police, private security, ground services, airline companies work at the airport and its terminals and interact with the passengers due to their duties. All of the staff concerned; It is beneficial to regularly receive training on issues such as communication, service quality, customer satisfaction. Because, it is not possible for the average passenger to know which institution the staff they are in contact with, and even if the institution can distinguish which personnel, they will be able to hold the terminal operator as a source of dissatisfaction and be the source of dissatisfaction. In this context, first of all, training activities for the personnel should be emphasized. With the launch of Istanbul airport, an important step has been taken for Turkey to become a transfer Center for international flights. Transit passengers are also among the major sources of revenue for retailer businesses. For this reason, it is beneficial to develop retailing practices for transit passengers.

Turkish Studies - Social, 15(3) 
Especially for the passengers traveling for touristic purposes, the fact that the time to visit the country again is uncertain or that it will be after a long time may increase the feeling of purchasing gifts / souvenirs for passengers. In addition, the fact that they cannot spend the money in their pockets in their own country will reinforce this impulse. In this context, it is beneficial to increase the variety of products with low prices, gifts, and souvenirs, in order to spend the last money in the pocket at retail points. The aviation sector is one of the sectors that have been affected by the COVID - 19 pandemic that has emerged in China and affected the world. Airlines and airports have to develop new measures for the post-pandemic. In this context, it is useful to diversify the products such as personal cleaning, disinfectant, mask, perfume that cabin crews and passengers may need during their travels. It should not be ignored that those who come to the terminal to meet passengers, send passengers and airport employees are potential customers, and efforts should be made to sell products and services to them.

Keywords: Retailing, Airport Retailing, Terminal Retailing, Airport Terminal Retailing.

Öz: Bu makalede ABD'de 1978 yılında, Türkiye'de de 2003 yılında başlayan havacılık sektöründeki serbestleşme hareketleri sonrası gelişen ve de önem kazanan havalimanı perakendeciliğinin önemi ve gelişiminin incelenmesi amaçlanmaktadır. Türkiye'nin de dünya turizm ve havacılık pastasından aldığı payın her geçen gün arttığını ve de İstanbul Havalimanı'nın hizmete açılması ile İstanbul'un özellikle transit yolcu pazarında daha da büyüyerek mevcut konumunu güçlendirecek olması konuyu daha da önemli hale getirmektedir. Havacılık sektöründe havayolları ile başlayan özelleştirme hareketleri, devlete ait havayollarının yavaş yavaş ortadan kalkmasına ve yerlerini özel havayollarının doldurmasına sebep olmuştur. Ulusal ve uluslararası düzenlemeler sonrası yer hizmeti kuruluşları, ikram hizmeti kuruluşları, havalimanı ve terminal işletmeleri de özelleştirilmiştir. Özelleştirme neticesinde terminal işletmecileri gelirlerini arttırmak için perakendecilik gelirlerine odaklanmaya başlamışlardır. Terminal perakendeciliği ilk olarak duty free diye adlandırılan gümrüksüz mağazacılığa odaklanmış olsa da son yıllarda diğer perakendecilik gelirlerinin de potansiyelinin farkına varılmıştır. Havalimanları giriş ve çıkış anlamında kontrollerin yoğun olduğu alanlar olduğu için perakendecilik yapılacak alanlar da sınırlı tutulmaktadır. Terminale girişten uçağa binene kadarki süreçte zaman kısıtlı olduğu için terminal perakendeciliği daha fazla özen gösterilmesi gereken bir alana dönüşmüştür. Küresel ticaret içerisinde e-ticaret perakendeciliğinden sonra en fazla büyüyen perakende sektörü olduğu için daha da önem kazanmaktadır. Bu amaçla daha havalimanı perakendeciliği konusunda daha önceden yapılmış çalışmalar ve elde edilen bulgular derlenmekte, havalimanı perakendeciliğinin gelişimine, yolcuların havalimanında satın alma davranışlarını etkileyen unsurlara yer verilmekte, havalimanı perakendecilik türleri açıklanmakta ve bu alanda faaliyet gösteren işletmelere öneriler sunulmaktadır.

Anahtar Kelimeler: Perakendecilik, Havalimanı perakendeciliği, Terminal perakendeciliği, Havalimanı Terminal Perakendeciliği.

\section{Giriş}

1978 y1lında Amerika'da sivil havacılık sektöründe başlayan serbestleşme hareketleri hızla dünyaya yayılmış ve halen de devam etmektedir. Sektördeki büyüme öncelikle havayollarında başlamış olup, 1990'lı yıllardan itibaren de havalimanları ve havalimanı terminallerinin özelleştirilmesi ile devam etmektedir.

Özellikle düşük maliyetli havayollarının (low cost carrier) büyümesi ile birlikte havayolu ile seyahat eden yolcu sayısında ciddi artışlar meydana gelmiştir. Bu artışlar sayesinde havalimanlarında geçirilen zamanlarda da artış sağlanmış bu da havalimanlarındaki perakendecilik faaliyetlerinin önem kazanmasına sebep olmuştur. Türkiye'de 2003 yılında başlayan serbestleşme uygulamaları ile oluşturulan; her ile en az bir havalimanı yapılması veya her 100 km'de bir havalimanı olması tarzında politikalar çerçevesinde Türk havacılık sektörü de büyümeden payına düşeni fazlasıyla almış ve almaya devam etmektedir.

Yolcuların hava aracına erişebilirliği konusunda dünya ortalaması $\% 74,41$ iken, ülkemiz açısından bu oran \%91,34 tür (SHGM, 2019). Türkiye'de havac1lık sektörünün büyüme ortalaması, 
dünya ortalamasının yaklaşık 3 katıdır. IATA'nın çizdiği projeksiyona göre, 2036 yılına kadar Türkiye'nin; yolcu sayısı bakımından Dünya'da 9. Sıraya yükseleceği öngörülmekte olup ayn1 zamanda 20 yıllık süreçte yolcu sayısını 119 milyon artırarak en hızlı büyüyen 5. pazar olacağ beklenmektedir (IATA, 2017). Özellikle yeni açılan İstanbul Havalimanı'nın jeopolitik konumundan dolayı büyümeye olumlu katkı yapması beklenmektedir.

Yolcu, uçak ve yük trafiğinde son yıllarda dünya ortalamalarına göre ülkemizde önemli artışlar gerçekleşmiştir. Toplam yolcu sayısı, son 16 yılda \%510 artarak 210 milyona, uçak trafiği $\% 281$ artarak 2.017.763'e ve toplam yük miktarı \%296 artarak 3.821.894 tona ulaşmıştır. 2003 y1lından bugüne uygulanan politikalar sonucunda, havayolu şirketlerimizin uçak sayıs1 \%218, koltuk kapasitesi \%253, kargo kapasitesi \%625 artmış, yurt içinde ve yurt dışında uçulan toplam nokta sayısı 374'e ulaşmıştır (SHGM, 2018 faaliyet raporu).

A\&T Bank Perakende Sektörü Raporu (2019) ve Uluslararası danışmanlık firması KPMG'nin 2019 Sektörel Bakış - Perakende raporunda da havalimanı perakendeciliğinin önemi vurgulanmaktadır. Her iki raporda da dünyada e-ticaretten sonra en çok büyüme gösteren perakendecilik havalimanı perakendeciliği olduğu ifade edilmekte; özellikle İstanbul'a Çin ve Ortadoğu ülkelerinden gelen yolcuların perakende ürünlere olan talebinin artacağı vurgulanmaktadır. İstanbul Havalimanı'nın yöneticilerinin de yapmış olduğu açıklamalar ve de açıkladığı beklenti tahminleri bu görüşü desteklemektedir (https://www.igairport.com/tr/basin-bultenleri/iga-ceosukadri-samsunlu-istanbul-havalimanini-bbcye-anlatti).

\section{Havalimanı Perakendeciliğinin Gelişimi}

Havayolu işletmelerinin, havalimanı ve havalimanı terminallerinin özelleştirilmesiyle beraber, havalimanı ve terminal işletmecileri gelir kaynaklarını arttırmak için son yıllarda çeşitli stratejiler geliştirmişlerdir. 1960'll yıllarda hava istasyonu olarak tanımlanan havalimanları, 1970'li yıllarda alışveriş merkezi, 1980'li yıllarda ticaret merkezi, 1990'lı yıllardan sonra da eğlence merkezi şeklinde konumlanmaya başlamışlardır. Günümüze bakılırsa aynı zamanda alışveriş+ticaret+eğlence merkezi olarak faaliyetlerini sürdürdükleri düşünülmektedir.

(http://www.havayolu101.com/2011/08/10/markalar-havalimanini-yeniden-kesfediyor/)

İlk duty free (gümrüksüz) mağaza, İrlanda'nın Shannon Havalimanı'nda 1947 yılında açılmış olup, Türkiye'deki ilk gümrüksüz mağaza ise İstanbul Atatürk (Yeşilköy) Havalimanı'nda 22 Şubat 1972 tarihinde faaliyetine başlamıştır (http://www.havayolu101.com/2012/08/17/altifarkli-havalimani-musterisi). Türkiye'deki havalimanı özelleştirmeleri ile beraber havalimanlarında yer alan gümrüksüz mağaza sayısı hızlı bir şekilde artış göstermiştir. Ticaret Bakanlığı'nın verilerine göre, 07.11.2019 itibariyle Türkiye'de gümrüksüz satış yapan mağaza sayısı 286 olup bunların 211 adedi hava gümrük kapılarında yer almaktadır.

(https://ticaret.gov.tr/data/5d63d89d13b8762f7c43a738/32-gumruksuz \%20Satis\%20 Magazasi \%20Sayilari.pdf) DHMİ'nin yolcu istatistiklerine göre 2009 yılında diş hat yolcusu 44,2 milyon iken 2019 yılında 108,6 milyona ulaşmıştır (https://www.dhmi.gov.tr/sayfalar/istatistik.aspx). Diş hat yolcu sayısındaki hızlı artışın havalimanı perakendecilik faaliyetlerine olumlu katkı göstereceği aşikardır.

Thompson (2007:7), havalimanları için perakende gelirlerinin çok önemli kar sağlayıcı faktör olduğunu ifade etmektedir. Avrupa Uluslararası Havaalanları Konseyi (ACI EUROPE ) tarafından 23-25 Nisan 2012 tarihleri arasında Oslo Havalimanı'nın ev sahipliğinde düzenlenen 21. Havaalanları Ticaret Konferans ve Fuarı'nda (Airport Trading Conference \& Exhibition ), her tür havalimanlarındaki ticari gelirlerin arttırılmasının önemi vurgulanmış olup havalimanı perakendeciliğinin güçlü performans gösterdiği vurgulanmıştır. Global Havalimanı Perakendecilik raporu, global çapta gümrüksüz mağaza (duty free) satışlarının 75,4 milyar \$ seviyesinde olduğunu 
ve bunların içinde havalimanı perakendeciliğinin cirosunun 40 milyar \$'a ulaştığını belirtmektedir. (Global Airport Retailing Report, 2017-2022).

Aynı savı destekleyen fakat böyle olmasını eleştiren bir görüş de İrlanda merkezli düşük maliyetli havayolu (LCC) firması RYANAIR CEO'su Michael O'Leary'dan gelmiştir. 15 Mart 2012 tarihinde CNN INT'a yaptığı açıklamada havalimanlarının "Uluslararası alışveriş merkezleri" haline geldiğini ancak bu durumun havayolları açısından gereksiz yere maliyetleri arttırdığını ifade etmiştir (Juliet Mann, http://edition.cnn.com/2012/03/08/business/mpe-ryanair-ceo/index.html).

Havalimanlarında perakendecilik faaliyetlerinin yürütüldüğü fiziki mekânsal ayrıma bakıldığı zaman karşımıza iki temel ayrım çıkmaktadır: Kara tarafı ve hava tarafı. Graham (2009:111), çalışmasında havalimanında yapılan perakende satışların \%55'inin hava tarafında \%34'ünün ise kara tarafinda yapıldığını belirtmektedir.

Kara Tarafi: Terminal binasına giriş ile başlayıp bilet kontrol işlemlerinin yürütüldüğü, bagajların teslim edildiği, yolcu gönderilecekse vedalaşmanın yapıldı̆̆ı, bilet satış ve turizm acentelerinin ofislerinin yer aldığı bilet satın alınabilen alanları kapsayan uçağa binmeden önceki son güvenlik kontrollerinin yapıldığ 1 alanlardır.

Hava Tarafi: Son güvenlikten sonraki sadece görevli personelin ve uçağa binecek yolcuların geçiş yapabildiği, dış hat terminallerinde pasaport kontrolünün gerçekleştirildikten sonra ulaşılan, dış hatlardan gelen yolcuların da gümrük çıkış işlemlerini gerçekleştirmeden önceki bulundukları alanlardır.

Yolcuların, tüm kontrolleri bittikten sonra kalan zamanlarını değerlendirme aracı olarak hava tarafındaki perakende noktalarını ziyaret etme ihtimalleri yüksektir. Havalimanını kullanan transit yolcuların da burada bulunması, hava tarafinda yürütülen perakendecilik faaliyetlerine daha da özen gösterilmesini gerektirmektedir.

Londra Heathrow Havalimanı'nın 2018 yılı raporlarına göre, havalimanının yıllık gelirinin 2,97 milyar GBP olduğu ve bunun 716 milyon GBP'lik kısmının perakende gelirlerinden olduğu anlaşılmaktadır. Aynı raporda, havalimanı işletmecisinin perakende gelirlerinin; \%45'inin mağazalardan, \%17,8'inin diğer perakendecilik faaliyetlerinden, 17,5'inin otoparktan, \%\%8,5'inin ikram servisinden (catering) ve \%10,9'unun da diğer gelirlerden elde ettikleri görülmektedir. 1999 yılında Avrupa Birliği'nin kendi içinde seyahat eden yolculara duty free satışları yasaklaması ile 4,60 GBP'den 3,80 GBP'ye gerilemiş olan yolcu başı perakende gelirlerinin, 2018 yılında 8,94 GBP'a ulaştığı görülmektedir.

Havalimanı terminal perakendeciliği konusunda literatürün 1990'lardan sonra oluşmaya başladığı görülmektedir. Bu da sektördeki ivmeye paralel bir gelişim göstermektedir. Literatür taramasında da konunun çok boyutlu olarak irdelendiği görülmektedir.

Zhang ve Zhang (1997:295), havalimanları için, fiyatlandırma yapar iken, havacılıktan elde edilen gelirler ile ticari gelirlerin birlikte arttırılabilmesi için karar almada çapraz işbirliğinin arttırılmasını öneren sosyal gereklilikten bahsetmişlerdir.

Freathy ve O'Connell (1999:122) yolcuların satın alma ortamı anlamında havalimanlarını geçici alan olarak konumladıklarını ifade etmektedirler. Bu sebeple yolcuların önceliklerinin hızlı ve kaliteli hizmet almak olduğunu, bu sebeple de havalimanlarındaki perakendecilik faaliyetlerinin çeşitlendirilmesinde dikkatli çalışılması gerektiğini önermektedirler.

Topping (2010), terminal perakendeciliğinde de promosyonların çok önemli olduğunu vurgulamakta ve iyi planlanmış promosyon faaliyetlerinin satışları \% 400'lere varan oranlarda arttırabileceğini vurgulamaktadır. 
Son yıllarda havalimanlarının perakende faaliyetleri ile öne çıkmaya başlaması ve de alışveriş merkezi benzeri uygulamalarda bulunmaları da literatürü destekler niteliktedir.

\section{Havalimanı Terminal Perakendeciliğini Etkileyen Unsurlar}

Crawford ve Melewar (2003), seyahat edenler için havalimanlarında alışverișin çok önemli bir faaliyet olduğunu ifade etmektedir. Bu sebeple de havalimanı operasyonları içerisinde perakendecilik faaliyetlerinin çok önemli bir yeri olduğundan bahsetmektedirler, bu açıdan perakendecilik faaliyetlerine farklı açılardan bakmakta fayda vardır.

\subsection{Yolcu Yapısı}

Havalimanı perakendeciliğini etkileyen faktörler çok sayıdadır. En önemlilerinden birisi de yolcuların taleplerindeki değişimlerdir. Yolcular daha fazla eğitimli ve de daha fazla seyahat eder hale geldikleri için daha seçici hale gelmişlerdir. Özellikle internet kullanımının yaygınlaşmasına paralel olarak ürünler/hizmetler ve de bunları sunanlar hakkında daha hızlı ve kolay şekilde çok fazla bilgi edinme imkanları artmıştır. Bu durum hem tüketiciler hem de işletmeler açısından da faydalı sonuçlar doğurmaktadır. İşletmeler bu bilgileri kullanarak gelirlerini arttırabileceklerdir.

Keown (1989), turistlerin satın alma davranışlarını inceleyen çalışmasında, turistlerin ait oldukları kültürün, içinde bulundukları ekonomik koşulların ve bireylerin yaşam tarzlarının satın alma ya da almama davranışlarında etkili olduğunu ifade etmektedir. Genellikle kültür, sosyal faktörler, bireysel özellikler bireylerin satın alma ya da almama davranışlarını etkileyebilmektedir. Yapılan benzeri çalışmada da yolcuların demografik faktörlerinin, seyahat amacının ve seyahat sırasında yanında bulunanların da etkili olduğu bulgulanmıştır (Perng vd. 2010:208). Geuens vd.(2004), Baron ve Wass (1996), Laesser ve Dolnicar (2012) satın almada bulunan yolcuların sosyal ve demografik özelliklerine, plansız satın alma davranışlarına ve satın alma bütçelerine odaklanmışlardır. Cinsiyet açısından kadınlarda erkeklere göre satın alma davranışı açısından anlamlı farklılıklar tespit etmişlerdir.

Appold ve Kasarda (2006), Amerika'daki havalimanı perakendecileri için satışlara en büyük etki sağlayan faktörün terminali kullanan yolcuların demografik özelliklerine bağlı olduğunu, bunun da yolcu sayısına göre şekillendiğini belirtmektedirler. Yolcu sayısının kontrolünün de perakendecilerin elinde olmadığını vurgulamışlardır. Aynı zamanda yiyeceklere olan talebin en yüksek seviyede olduğunu belirtip, özellikli perakende ürünlere olan talebin büyük kapasitelere sahip aktarma merkezi şeklindeki terminallerde artacağını ifade etmektedirler.

Lee ve Kacen (2008), planlı ve plansız satın alma davranışı üzerinde yaptıkları çalışmalarında bireylerin içinde bulundukları kültüre odaklanmışlardır. Bireylerin ailelerinin ve satın alma kararı verilmesi sırasında yakınlarında bulunanların satın alma kararlarında etkilerini bulgulamışlardır. Demografik değişkenlerin yanı sıra, havalimanında geçirilen zaman, seyahat amacı, seyahat sırasında yanında bulunanlar, seyahat sıklığı da satın alma davranışı üzerinde etkili olmaktadır. Perng vd. (2010:282), cinsiyete göre perakende ürünleri satın alma davranışını inceledikleri çalışmalarında, kadınların harcamalarının hazır giyim, parfümeri ve kitap/dergi şeklinde olduğunu, erkeklerin ise elektronik cihazlara daha fazla ilgi gösterdiklerini bulgulamışlardır.

Stasiulevicuis (2012), havalimanlarında gerçekleştirilen harcama davranışlarının sahip olunan harcanabilir zaman ile ilişkisini incelemiştir. Yolcuların yeterince zamanları olduğunu düşünmedikleri zaman satın alma eğiliminde olmadıklarını tespit etmiştir.

Türkiye ile birlikte 5 ülkede 12 havalimanında hizmet veren ATÜ Duty Free'nin Genel Müdürü Arcan (2014), Ortadoğu, Uzakdoğu ülkelerinden ve Rusya'dan gelen yolcuların, markalı pahalı ürünleri tercih ettiğini, batılı yolcuların ise daha az oranda harcama yaptığını belirtmektedir. Arcan (2014), hangi ülke vatandaşlarının hangi ürünleri daha çok satın aldıklarını tespit ettiklerini, sonrasında da terminal işletmecisi ile işbirliği yaparak, gelen uçağı yolcuların daha çok tercih 
edecekleri ürünlerin bulunduğu mağazalara yakın kapıya (gate) yaklaştırıldığını ifade etmektedir (http://www.airporthaber.com/havacilik-haberleri/duty-free-taktikleri.html).

Graham (2009), özellikle yılda birden fazla tatil amaçlı seyahat eden genç yolcuların daha fazla harcama yaptığını, düşük maliyetli havayolu ile uçan yolcuların da yiyecek içecek harcamalarının daha fazla olduğunu belirtmektedir. Graham (2009), tüketim ürünlerinden alınan vergi oranlarının yüksek olduğu ülkelerden gelen yolcuların, gümrüksüzz satış yapan mağazaları daha çok tercih ettiklerini ifade etmektedir.

Torres vd. (2005), havalimanını kullanan yolcuların tatil amaçlı mı yoksa iş amaçlı mı seyahat ettiklerini incelemiş ve tatil amaçlı olanların daha fazla harcamada bulunduğunu tespit etmiştir. Ayrıca bekleme zamanı ile harcama arasında ilişki bulunmadığını bulgulamıştır. Huang ve Kuai (2006), terminalde alış veriş yapanlar ile uçuş esnasında alışveriş yapanların davranışlarını incelemişlerdir. Satın almada bulunanların almayanlara göre, yaşça daha büyük, daha fazla gelire sahip, marka ve fiyat konusunda bilinçli hareket eden ve plansız alışverişi daha fazla yapan yolcular olduklarını bulgulamışlardır.

Manchester Havalimanı tarafından yapılan bir çalışmada, havalimanında alışveriş yapanların tüketim eğilimleri göz önüne alınarak beş farklı müşteri tipine ayrıldığı görülmektedir (Graham, 2008:191):

- Havalimanı alışverişkolikleri (Airport Shopaholic): Havalimanında kontroller sonrası kendisini alışverişe çok kaptıranlardır. Tatile çıkan mutlu, genç kadın yolcularda daha yaygın görülür.

- Tatmin olmamış alışverişçiler (Unfulfilled Shopper): Sik seyahat ettikleri için kıyaslama yapabilir, bilinçli müşterilerdir. Bu gruptaki müşteriler genellikle iş veya tatil amaçlı seyahat eden genç profesyonellerden oluşmaktadır.

- Tedirgin Yolcu (Agitated Passenger): Havalimanındaki ürünlerin pahalı olacağ1 tedirginliği yaşayan, hayal kırıklığı içerisindeki genç, orta sınıf gelir tabakasından yolculardir.

- Değer arayanlar (Value Seeker): Genellikle bütçesi düşük olan ve bu bütçe ile satın aldıkları ürün / hizmetlerden maksimum fayda görmek isteyenlerdir. Senede bir kez havayolu seyahati yapan öğrenci veya emekli yolcu.

- Potansiyel Müşteriler (Unlikely Shoppers): Sık uçuş yapan, havalimanında satın alma davranışı gösteren sık uçan iş adamları ve her şeyi ölçüp biçen yaşlı erkek yolcular.

Jarach (2005:73), ise havalimanı perakendecilerinin karşılaşabilecekleri müşteri tiplerini 5 kategoriye ayırmıştır:

- Seyahat edenler

- Yolcu karşılayan ve uğurlayanlar

- Havalimanı ve havayolu çalışanları

- Havalimanı ziyaretçileri

- Havalimanı ile iş yapan firma temsilcileri

Jarach'ın oluşturduğu sınıflamaya göre ise havalimanında faaliyet yürüten perakendeci işletmeciler için karşılaşabilecekleri müşteri tipleri yer almaktadır. Dolayısıyla perakendeci işletmelerin yolcuların yanında diğer potansiyel müşteriler için de tercih edilmelerini sağlayacak stratejiler geliştirmesinde fayda vardır. Özellikle yolcu tipolojisine göre yeni stratejiler geliştirilmesi perakende gelirlerinin arttırılmasına yardımcı olacaktır. Havalimanını kullanan yolcu milliyetleri 
araştırılıp en çok kullanan milliyete ve de en fazla harcamada bulunan milliyete göre ürün çeşitlendirilmesinde fayda görülmektedir.

\subsection{Satın Alma Ortamı}

Entwistle (2007), havalimanı terminalinde yer alan mağazalardan rahatsızlık duyan yolcu oranının \%5 olduğunu ifade etmektedir. Kalan \%95'lik kısım ise mağaza çeşitliliğinin terminal ortamına renk kattığını ve bu durumdan memnun olduklarını ifade etmektedirler.

Kim ve Shin (2001:150), havalimanlarındaki mağaza çeşitlerinin terminalin büyüklüğüne ve terminali kullanan yolcu yapısına göre farklılık gösterdiğini belirtmektedirler. Kitap satış, cep telefonu ve aksesuarları, eczane, hazır giyim, bavul, hediyelik eşya, gümrüksüz satış (duty free), restoran, kafeterya, oto kiralama gibi hizmet sunan işletmelere ait mağazalarda perakendecilik faaliyetleri sürdürülmektedir.

Jarach (2001:123), havalimanlarında sürdürülen ticari faaliyetleri, "ticari faaliyetler, yolculara dönük hizmetler, kongre hizmetleri, lojistik hizmetler ve danışma hizmetleri” olmak üzere 5'e ayırmaktadır. Son yıllarda görüldüğ̈̈ üzere havalimanı terminalleri uçağa binişe hizmet etmenin yanında alışveriş merkezi olarak da konumlandırılmaya başlanmıştır.

Havacılık oskarları olarak nitelendirilen ödülleriyle bilinen SKYTRAX'1n 2019 y1lında, 100'den fazla milliyetten katılımcının olduğu, 550 havalimanını kapsayan yaklaşık 12 milyon yolcudan elde ettiği verilere dayanarak yayınladığı Havalimanı Sektörü Ödülleri raporuna göre en iyi alışveriş ortamı sağlayan havalimanları sıralaması şu şekilde oluşmuştur (World's Best Airport Shopping 2019, https://www.worldairportawards.com/worlds-best-airport-shopping-2019/)

\section{Londra Heathrow}

2. Hong Kong

3. Seul Incheon

4. Singapur Changi

5. Dubai

6. Doha Hamad

7. Paris CDG

8. Frankfurt

9. Milan Malpensa

\section{Roma Fiumicino}

Dünyanın önde gelen havalimanlarında perakendecilik gelirlerinin arttırılması amacıyla farklı uygulamalar bulunmaktadır. Türkiye'deki havalimanı terminal işletmecilerinin, dünyadaki ödüllü havalimanlarının perakendecilik uygulamalarını örnek alarak kendi hizmet süreçlerini geliştirebilecekleri düşünülmektedir. Dünyadaki örnek uygulamalara bakıldığı zaman profesyonelce hazırlanmış, yenilikçi pazarlama çabaları ile karşılaşılmaktadır.

Frankfurt Havalimanı'nda B5-B9 arası kapılarda yolcuların karşısına duty free mağazalarında en çok tercih edilen, yeni ürünler ve özel teklif içeren \%30'a varan indirimli satış fiyatı bulunan 60 adet ürünün görselinin yerleştirildiği duvar çıkmaktadır. Yolcu satın almak istediği ütünün kare kodunu (QR Code) akıllı telefonuna okutup ürünü sanal alışveriş sepetine atabilmektedir. Ürün seçim işlemi bittikten en geç 15 dakika içerisinde, en yakın teslim noktasına ürünler getirilmekte ve ödeme yapılmaktadır. 
(http://www.passengerselfservice.com/2013/05/10/frankfurt-airport-fra-is-testing-a-qr-wall-forshopping).

Frankfurt Havalimanı yolcularına uçuştan en az 12 saat önce olmak kaydıyla internet üzerinden havalimanında satın alacakları duty free ürünleri için ön sipariş verme imkanı sunmaktadır. Yolcunun siparişi sırasında uçuş numarasını ve uçacağı hattı bildirmesi istenmekte ve uçuş günü uçağa bineceği kapıya (gate) en yakın mağazadan teslim alabilmesini sağlamaktadır. Bu uygulama terminal işletmecisinin yürüttüğ̈ "sizi burada görmek harika (Great to have you here)" isimli hizmet kalitesi programının bir parçası olarak lanse edilmektedir (http://www.airparks.co.uk/gatwickairport-shopping.html).

Londra Gatwick Havalimanı'nda İngiltere ve AB içerisinde seyahat eden yolculara yönelik ücretsiz Shop\&Drop (al ve bırak) servisi bulunmaktadır (http://www.airparks.co.uk/gatwick-airportshopping.html). Yolcu mağazadan satın aldığı ürünleri mağazadaki yetkiliye teslim etmekte ve yolcu dönünceye kadar güvenli bir şekilde saklamaktadırlar. Havalimanından alışverişi yapmayı özendirip seyahat dönüşünde yolcuya satın aldığı ürünler terminalde bagaj teslimden sonraki aşamada teslim edilmektedir. Böylelikle yolcunun seyahat sırasında satın aldığ 1 ürünleri yanında taşımakla ilgili tüm kaygıları ve dezavantajları ortadan kaldırılmakta ve tüketicinin havalimanında gerçekleştirdiği harcamalar maksimize edilmeye çalışılmaktadır.

İngiliz perakende devi Tesco ise 2012 yılının Ağustos ayında Londra Gatwick Havalimanı'nda deneme amaçlı sanal mağazasını açmıştır. Slogan olarak da "seyahat dönüşü buzdolabınız boş olmasın" ifadesini (Come home to a full fridge, tesco.com) seçmiştir. Yolcuların havalimanında uçuşunu beklerken, Tesco'nun yerleştirdiği sanal mağaza duvarlarında (shopping wall) akıllı telefonları yardımıyla dönüşte ihtiyacı olacak ürünleri seçip sanal sepete koymalarını ve ödeme yapmalarını sağlamıştır. Tüketiciye satın aldığı ürünü istediği tarihte istediği yerde (havalimanı, ofis, ev...) teslim imkanı sunmaktadır. Böylelikle müşterilerine hem her zaman yanlarında olduğu ve ihtiyaçları için çözüm sunduğu hem de inovatif bir işletme oldukları vurgusunu yapabilmişlerdir (http://www.retail-week.com/sectors/food/in-pictures-tesco-launches-virtualshopping-wall-at-gatwick-airport/5039449.article).

\section{3. İçü̈düsel Satın alma Davranışı}

Geuens vd.(2004), turistler açısından alışverişi, tatil ihtiyacını karşılamanın bütünleyicisi olarak tanımlamakta ve turistlerde görülen alışveriş davranışının önemine değinmektedirler. Hobson (2000) ise, uluslararası uçuş yapan turistlerce gümrüksüz (duty free) mağazalarda gerçekleştirilen satın almanın önemli olduğunu ve gerçekleştirdikleri seyahatin tamamlayıcısı olduğunu ifade etmektedir. Böylelikle seyahat eden turistler gittikleri tatil bölgesine kullandıkları havalimanları yoluyla da kazanç sağladıklarını, bu kazançların da havalimanı işletmecileri için azımsanmayacak bir gelir kaynağı olduğunu belirtmektedirler.

Entwistle (2007), havalimanını kullanan yolcuların \%60'tan fazlasının terminale gelmeden önce harcama yapmayı planladığını belirtmektedir. Omar ve Kent (2001), havalimanında gerçekleştirilen satın alma davranışlarının ortamdaki çevre faktörlerinden, pazarlama çabalarından ve alışveriş yapan diğer tüketicilerden etkilendiğini, böylelikle içgüdüsel (plansız) satın almanın gerçekleştiğini, Gatwick Havalimanı'nda yolcular ile yaptıkları çalışmalarında tespit etmişlerdir.

Arcan (2014), havalimanında pasaport kontrolden sonraki alışverişin yüzde 65-70'inin içgüdüsel alışveriş olduğunu, yani daha önceden planlanmamış, mağazada karar verilen alışveriş olduğunu vurgulamaktadır (http://www.airporthaber.com/havacilik-haberleri/duty-freetaktikleri.html).

Baron ve Wass (1996), yolcuların havalimanındaki satın alma davranışlarının arkasındaki sebeplere dikkat çekmektedir. Yazarlar, yolcuların havalimanı içerisinde mağazalara niçin göz attıklarını / göz atmadıklarını ve niçin satın aldıklarına odaklanmaktadırlar. Ayrıca satın alma 
davranışının önceden planlı bir davranış olup olmadığını araştırmaktadırlar. Çalışma sonucunda kadın ve erkekler arasında anlamlı fark bulgulanmamıştır.

Freathy ve O'Connell (2012) tarafından yapılan araştırma; yolcuların havalimanında yaptıkları harcamaların \%72'sinin önceden planlamış olduklarını, satın alma sebeplerinin \%65'inin kişisel ihtiyaçları giderme ve hediye etme amaçlı olduğunu ortaya koymaktadır. Dolayısıyla havayolu ile seyahat eden yolcularda planlı satın alma davranışının yaygın olduğu değerlendirilmektedir. Yolcuların havalimanı perakende noktalarında ürünün farkına vardığı anda gelişen satın alma isteği sonucu otaya çıkan içgüdüsel satın almaya (impulse buying) bakıldığı zaman alkollü içecekler, parfüm/kozmetik ve mücevher grubu ürünlerde yoğunluk olduğu görülmektedir (Freathy ve O'Connell, 2012:408). Yapılan araştırmalar, satın alma eylemini erkeklere göre kadınların daha fazla gösterdiğini ortaya koymaktadır (Timothy, 2005:84). Bu da cinsiyete göre satınalma davranışlarını inceler iken göz önüne alınması gereken bir detaydır.

Son yıllarda elektronik reklam araçlarının hızlı gelişimi ve de akıllı telefon kullanımın yaygınlaşmış olması, tüketiciler üzerinde daha hızlı sonuç alınabilen doğrudan pazarlama taktiklerinin geliştirilmesine yardımcı olmaktadır. Bu bağlamda havalimanlarında da yolcular üzerinde satın alma içgüdülerini harekete geçirerek satın alma isteği oluşturacak çabalara ağırlık verilmesinde fayda görülmektedir.

\subsection{Havalimanının Büyüklüğü}

Tovar ve Martín-Cejas (2009) İspanya'daki havalimanlarındaki çalışmasına göre, aktarma merkezi (hub airports) ve büyük çapta faaliyet gösteren turistik havalimanlarının küçük çaptaki havalimanlarına göre daha fazla sayıda uluslararası yolcu çekmesi beklenmektedir. Böylece yolcu sayısının artışına paralel havalimanlarının perakende gelirleri artış gösterecektir.

Geuens, vd. (2004), havalimanının sahip olduğu olanakların ve yolculara sunduğu alışveriş seçeneklerinin önemine değinmişlerdir. Benzer şekilde Torres vd. (2005), terminal perakende noktalarındaki kaliteli hizmetlerin, yolcuların satın alma davranışı üzerindeki etkisini vurgulamaktadırlar. Perng vd. (2010) havalimanı alışverişçilerinin daha önceden deneyimlediği ve bildiği markaları tercih ettiklerini ve ürün çeşitliliğine odaklandıklarını ifade etmektedirler.

\subsection{Perakende Alanlarının Yeterliliği}

Havalimanlarının gelirlerinin havacılık dışı alanlardan da büyük artış göstermesiyle beraber terminal tasarımlarında perakende alanlarının arttırılması daha da önem kazanmıştır. Kiralanabilir alanların büyütülmesi, havalimanı terminal gelirlerinin artmasına yardımcı olacaktır.

Birçok havalimanı işletmecisi perakende alanlarına olan taleplerin artmasından dolayı daha fazla terminal alanını perakende noktasına dönüştürmeye başlamıştır. Liverpool John Lennon Havalimanı 2009 yılında $55.000 \mathrm{~m} 2$ olan perakende alanlarını $80.000 \mathrm{~m} 2$ 'ye yükseltmiştir. Böylelikle perakende gelirlerinde \%45'lik bir artış sağlamışlardır (Freathy ve O'Connell, 2012:401). Benham (2009: 9), çalışmasında uluslararası havalimanları için her bir milyon yolcu için en az $800 \mathrm{~m} 2$ perakende alanı olması gerektiğini belirtmektedir.

Hsu ve Chao (2005), havalimanı perakende noktalarında sunulan ürün ve hizmet çeşitliliğinin arttırılmasının, daha fazla alanda perakendecilik yapılmasının havalimanını kullanan yolcu sayısına doğru orantılı olarak perakende gelirlerinin artmasına katkı sağlayacağını ifade etmektedirler.

\subsection{Yolcuya Kalan Zaman}

Türkiye'deki havayollarının ve de havalimanı işletmecilerinin yolculara yönelik bilgilendirme mesajlarında, ortalama olarak; iç hat yolcularının en az 1 saat, dış hat yolcularının en az 2 saat önce havalimanında olması gerektiği bilgisi yer almaktadır. Dolayısıyla havalimanının 
bulunduğu şehre ve de uçuş saatine göre yolcular bu süreleri de göz önüne alarak havalimanına ulaşım süreçlerini ayarlamaktadırlar. Uçuşa kabule kadar ki süreç ne kadar hızlı bir şekilde atlatılırsa yolcuya alışveriş yapabilmesi için o kadar fazla zaman kalmaktadır. $\mathrm{Bu}$ sebeple havalimanı işletmecileri de yolcuya kalan zamanı artırmak ve de bu süreçteki memnuniyeti seviyesini yüksek tutmak için çaba göstermektedirler.

Yolcunun, havalimanına gelişinden uçağa biniş işlemlerinin tamamlanmasına kadarki sürecin hızlı ve problemsiz yürütülmesinde fayda bulunmaktadır. Perng vd.(2010) ve Gkritza vd. (2006), çalışmalarında güvenlik görevlilerinden kaynaklı memnuniyetsizliğin algılanan hizmet kalitesini ve satın alma davranışını negatif yönde etkilediğini bulgulamışlardır.

Arcan (2014), yolcunun hava tarafinda -pasaport kontrolü sonras1- geçirdiği her bir dakika için ortalama 8 cent daha fazla alışveriş yaptığını, dolayısıyla havalimanına girdiği andan itibaren otopark, güvenlik, check-in ve pasaport kontrol aşamasında bekleme zamanının azaltılmasının toplam alışveriş tutarını arttırdığını vurgulamaktadır (http://www.airporthaber.com/havacilikhaberleri/duty-free-taktikleri.html).

\section{Havalimanı Perakendeciliğinde Kontrat Türleri}

Havalimanı perakendeciliğinde, havalimanı işletmecisi kuruluş ile perakendeci işletmeler arasında farklı kapsamlarda sözleşmeler düzenlendiği görülmektedir. En sık düzenlenen sözleşmeler 4 farklı kategoride yer almaktadır (Freathy ve O'Connell, 1998:43).

\section{1. İmtiyaza Dayalı Perakendecilik}

En yaygın görülen sözleşme şeklidir. Havalimanı işletmecisi kuruluş, yapının sahibi olup genel olarak terminalin bakımından, aydınlatılmasından, ısıtılmasından ve temizliğinden sorumlu olur, kiracılar da satışlardan sorumludur. Bunun karşllı̆̆nda da kiracılarından, sabit kira, sabit kira+hasılattan pay veya direkt olarak hasılattan pay alma şeklinde kira tahsilatı yapmaktadır. Bazı havalimanı işletmecilerinin daha proaktif roller üstlenip yolcuların daha fazla satın alma davranışı göstermeleri için çaba göstermektedir.

Havalimanı işletmecisi mümkün olduğu kadar fazla kiracıya ulaşabilmek için gerekli altyapıyı hazırlamakla sorumludur. Kira sözleşmelerindeki süre, kira bedeli gibi detaylar işletmeden işletmeye farklıl1klar göstermektedir. En önemli kriter perakendecinin yapacak olduğu yatırıma bağlıdır. Yatırım miktarı az ise kısa süreli sözleşme, fazlaysa uzun süreli sözleşme yapıldığı görülmekte olup, diğer perakendeci işletmelere firsat yaratılması amacıyla sözleşmelerin 5 yıldan fazla süreyi kapsamaması gerektiği önerilmektedir (Doganis, 1992:150).

\subsection{Kurum Tarafından Gerçekleștirilen Perakendecilik}

Terminal işletmecisi firmanın, perakendecilik faaliyetlerini kendisinin yürüttüğü türdür. Satın alma, satma ve pazarlama faaliyetlerinin tamamı havalimanı işletmecisi tarafindan yürütülür. Özellikle, gümrüksüz mağazacılık, yiyecek-içecek ve otopark işletmeciliği üzerine odaklanılır. Yüksek seviyede uzmanlık ve tecrübe gerektiren perakendecilik türlerin sözleşme ile kiracılara devredildiği görülmektedir (Freathy ve O'Connell, 1998:53).

Perakende gelirlerinin tamamı havalimanı işletmecisine kaldığ 1 için avantajlı bir yöntem olarak düşünülebilir. Havalimanında yer alan perakende noktaların tamamı arasında, işbirliğinin maksimum seviyede sağlanarak reklam, tanıtım gibi faaliyetlerin daha kolay yapılıp başarılı sonuçlar alınmasını sağlamaktadır. Aynı zamanda havalimanını kullanan yolculara sunulan hizmetlerin tek bir standartta sunulmasına katkı sağlamaktadır. Avantajlarının yanında dezavantajları da mevcuttur. En önemlisi, havalimanı işletmecisi, sözleşme ile garanti altına aldığ 1 kira gelirlerinden uzak kalacaktır. Bu durum hazırlanacak finans planlarında garanti gelirleri azaltacağı için belirsizliğe yol açabilecektir. Bir diğeri de, perakendecilik faaliyetlerini başarılı bir şekilde sürdürmek için yeterli uzmanlığa sahip olunmamasıdır. Perakendecilik faaliyetleri; satın alma, depolama, satış gibi 
konularda uzmanlık gerektirmekte, bu da işletmeci firmanın odağının terminalden çok perakendeciliğe kaymasına sebep olarak asıl odaklanması gerekli olan faaliyetlerinden uzaklaşmasına sebep olacaktır.

\subsection{Yönetim Sözleşmesi}

Havalimanındaki perakende operasyonlarının, sözleşme yapılarak üçüncü bir kuruluşa devredilmesidir. Bu türde iki taraf arasında çok daha büyük çapta birbirine bağlllık ilişkisi ortaya çıkmakta ve resmi olarak havalimanı işletmeciliğine ortak olmasalar da ortak hareket etme zorunluluğu ortaya çıkmaktadır. Havalimanı işletmecisinin geçmişte perakendecilik deneyimin olmadığ 1 ya da yetersiz olduğu durumlarda sık görülen bir uygulamadır. Üçüncü kuruluş perakendecilik faaliyetlerinin operasyonunu sağlar ve de anlaşmaya göre havalimanı işletmecisine belirli bir rakam ya da kâr paylaşımı şeklinde yürütüldüğü görülmektedir. Böylelikle işletmeci firma perakendecilik ile alakalı uzmanlık eksikliğini bertaraf etmiş olur, aynı zamanda işi uzmanlarına bırakarak toplama perakende gelirlerini arttırma olanağı sağlamaktadır (Freathy ve O'Connell, 1998:55). Bu konuda Türkiye'den en güncel uygulama 29.10.2019'da resmi olarak açılışı yapılan ve 06.04.2020 tarihinde tam kapasite ile faaliyete geçen İstanbul Havalimanı'nda karşımıza çıkmaktadır. Havalimanının işletmecisi olan İGA Havalimanı İşletmesi A.Ş. ile 135 yıllık perakendecilik deneyimine sahip Gebr. Heinemann SE \& Co. KG ile ortaklı̆ğ bulunan Unifree

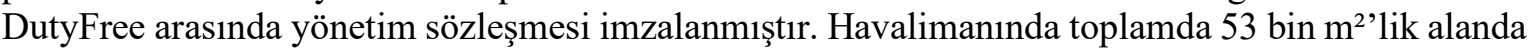
yer alan lüks butik mağazalar, Türk ürünlerini satıldığı mağazalar, duty free mağazalar 25 süreyle Unifree DutyFree tarafindan işletilecektir (https://www.igairport.com/tr/basin-bultenleri/dunyaninen-buyuk-duty-free-anlasmasi-imzalandi).

\subsection{Ortak Girişim Perakendeciliği}

Havalimanı özelleştirmelerinin hız kazanmasıyla beraber birçok firma terminal işletmeciliğine odaklanmış bu da sektörde işbirliklerinin artmasına sebep olmuştur. Perakendecilik açısından gerçekleşen ortaklıklar ise perakendecilik tecrübesi olan firmalar ile işletmecilik tecrübesi olan işletmelerin terminal işletmeciliğini ortak girişim olarak yürütmeleri şeklinde görülmektedir. Genel uygulama ortak girişimde taraflardan bir tanesinin yerel olmasıdır. Böylelikle girilen Pazar hakkında daha fazla bilgi ve tecrübeye sahip olunduğu için operasyonel faaliyetler kolaylaşmaktadır. Örneğin ICF Antalya Uluslararası Havalimanı Terminal 1 ve Terminal 2'deki gümrüksüz alanların işletmecisi olan NetNuance isimli firma \%45 Türk Net Holding \%55 Zürih merkezli Nuance Grup ortak girişimi ile faaliyetlerini yürütmektedir (http://www.netnuancedf.com/index.php?tarihce=1).

\section{Perakende Noktalarının Lokasyonunun Planlanması}

Yolcuların havalimanına iç hat uçuşlarda en az bir saat, dış hat uçuşlarında en az 2 saat önce gelmek durumunda olması ve uçuşa kayıt işlemleri sonrası geçirecekleri boş zamanlarının fazla olması havalimanında sunulan perakendecilik hizmetlerini daha da önemli kılmaktadır. Bu boş zamanların alışveriş yapılarak geçirilmesini sağlamaya yönelik faaliyetler her geçen gün daha da önem kazanmaktadır.

Scholvinck'in 2000 yılında geliştirdiği seyahat stres eğrisi dış hat uçacak olan bir yolcunun yaşadığı stresi ortaya koymaktadır. Bu eğriye göre seyahat stresi, evden çıkışla beraber artmaya başlamakta olup; havalimanına zamanında ulaşma sürecinde, terminale giriş ve uçuşa kayıt işlemleri (check-in) ile artış göstermekte ve gümrük kontrolü sırasında zirveye çıkmaktadır. Gümrük kontrol işlemlerinin sorunsuz atlatılmasıyla beraber yolcunun stresinde hızlı bir şekilde azalma ortaya çıkmaktadır (Crawford ve Melewar, 2003:90). Bireylerin stresinin azalış göstermesinin satın alma davranışı üzerinde yaratacağı pozitif etki aşikârdır. Bu sebeple perakende noktalarının tespitinde, mağaza yerleştirmede bu durumun da dikkate alınmasında fayda görülmektedir. 
Jarach (2005) bu konuda perakende noktaların ideal yerleşim planı olarak havaalanını üç bölüme ayırmıştır: kara tarafı giden yolcu salonu, hava tarafi giden yolcu salonu ve gelen yolcu salonu. Bu üç noktada bulunmas1 gereken mağaza çeşitliliği Tablo 1'de verilmektedir.

Tablo 1: Mağaza ve Hizmet Noktaları İçin Havaalanı Terminalinde İdeal Konumlanma Noktaları

\begin{tabular}{|l|l|l|}
\hline $\begin{array}{l}\text { Kara Tarafı } \\
\text { Giden Yolcu Salonu }\end{array}$ & $\begin{array}{l}\text { Hava Tarafı } \\
\text { Giden Yolcu Salonu }\end{array}$ & Gelen Yolcu Salonu \\
\hline Şarküteri (gourmet shop) & Duty free mağazalar & Eczane \\
\hline Kafe, bar ve restoranlar & Bar ve restoranlar & Bar ve restoranlar \\
\hline Terzi & Son dakika Duty free mağazaları & Danışma noktası \\
\hline Tematik mağazalar & Kuyumcu & Otel tanıtım noktası \\
\hline Moda ürün satan mağazalar & Döviz bürosu & Banka \\
\hline Gazete dergi satış noktaları & & Çiçekçi \\
\hline & & Araç kiralama ofisleri \\
\hline
\end{tabular}

Kaynak: Jarach, 2005: 78

Tablodan görüldüğü üzere yiyecek - içecek ünitelerin terminalin her noktasında yer alması önerilmekte, yolcunun uçağa binmeden önceki nokta olan hava tarafı giden yolcu salonu için ise duty free mağazaların konumlandırılması önerilmektedir.

Hsu ve Chao (2005), toplam ticari gelirleri arttırabilmek için mağaza lokasyonlarının yolcular için daha ulaşılabilir hale getirilmesini önermektedir. Entwistle (2007) ise çalışmasında yolcuların \%85'lik kısmının, mağazaların giden yolcuların çıkış kapılarına daha ulaşılabilir noktalarda olmasinı istediklerini belirtmektedir.

Duval (2007:201), havalimanlarında perakende noktaları için dört önemli faktöre dikkat çekmektedir. Bunlar:

- Mağazalar yolcuların yürüyüş yolu üzerinde olmalıdır. Mağazaya ulaşmak için yolunu değiştirmesine gerek olmamalıdır.

- Mağazalar uçağa biniş yapılacak kapı (gate) alanları ile aynı katta olmalıdır. Böylelikle yolcu uçuşunu beklerken mağazalara daha kolay göz atabilir.

- Mağazalar yolcuların pasaport ve güvenlik kontrollerini tamamladıktan sonra, ruhsal olarak da harcamaya hazır oldukları için yakın noktalara konumlandırılmasında yarar vardir.

- Yolcunun ilk bakışta çoğu mağazayı aynı anda görebilecek şekilde mağazaların konumlandırılmasında fayda bulunmaktadır. Böylelikle yolcunun satın alma dürtüleri daha kolay tetiklenebilir.

Perakende noktaların konumlandırılması esnasında yukarıda yer alan önerilere dikkat edilmesi, perakende gelirlerinin arttırılmasını mümkün kılacaktır. Terminal perakende gelirlerinin arttırılabilmesi için Kim ve Shin (2001:150), havalimanı işletmecilerine, havalimanı içerisindeki operasyonel faaliyetleri maksimum verimli hale getirip müșteri memnuniyetini maksimize etmelerini önermektedir. Bunun için de; mağaza lokasyonunun, mağazalar fiyat seviyesinin, marka çeşitliliğinin ve bilinirliliğinin, imajının, ürün kalitesinin ve hizmet sunum seviyesinin önemli olduğunu vurgulamaktadır.

Knight (2009), Perng vd., (2010), Kim ve Shin (2001) havalimanında sunulan hizmetlerin kalitesinin ve sunulan ürünlerin çeşitliliğinin arttırılmasının yolcu memnuniyetine olumlu katkısı olacağı yönünde çalışmaları bulunmaktadır. Singapur Changi Havalimanında yer alan, 5 katlı dikey sarmaşık bahçesi, çatısındaki yüzme havuzu, 4 adet sinema sunması, Yeni Delhi Indira Gandhi 
Uluslararası Havalimanında akıllı telefonlara yüklenen uygulama ile QR kod kullanılarak hızlı alışveriş yapma seçeneklerinin sunulması, Frankfurt Havalimanında da QR kod kullanılarak interaktif alışveriş duvarı üzerinde satın alma yapılabilmesi güncel memnuniyet arttırıcı ve perakende gelirleri arttırıcı uygulamalar olarak dikkat çekmektedir

(https://www.skyscanner.com.tr/haberler/ziyaret-etmeniz-gereken-11-ultra-modern-havaalani).

Türkiye'de özellikle son yıllarda hizmete açılan havalimanları, mimari yapıları ve çevre dostu yeşil bitki örtüsü ağırlıklı görüntüsüyle yolculardan da büyük beğeni görmektedir. Güvenlik noktalarındaki hızlı geçiş bölümleri, kuyruk çilesi çekmek istemeyen yolculara kolaylık sağlarken, özel yolcu salonlarındaki masaj, duş, yiyecek-içecek, eğlence sistemleri ile terminal içinde transfer hizmeti sunan mini golf araçları, seyahatleri daha da keyifli hale dönüştürmektedir. Yurtdışındaki bazı havalimanlarında sunulan hizmetler ise çok daha ilginçtir. Singapur Changi Havalimanı'nda kelebek bahçesi ve Japon balığı havuzu yer almakta, Güney Kore'deki Seul Incheon Havalimanı'nda ise uçuşlar arasında dinlenmek için yatar koltuk salonları yer almaktadır. Hollanda Amsterdam'daki Schiphol Havalimanı ise kütüphanesi, müzesi, mağazaları ve apron manzaralı terasıyla beğeni toplamaktadır. (http://www.airporthaber.com/havacilik-haberleri/eglenceye-ucuyoruz.html)

\section{Havalimanı Terminal İşletmecileri ve Perakendeci İşletmelere Öneriler}

Havalimanı işletmecilerinin ve de havalimanında faaliyet gösteren perakendeci işletmelerin faaliyetlerinin devamlılığını sağlayabilmek ve de kârlılıklarını arttırabilmek adına bu konuya daha fazla önem göstermeleri gerekmektedir.

Arthur D Little Uluslararası Danışmanlık Firması'nın Havalimanı Perakendeciliğinin Esasları (Mastering Airport Retail) isimli raporuna göre, havalimanı işletmecilerinin önümüzdeki y1llarda büyümeyi sürdürebilmek ve daha iyi performans sergileyebilmek için beş temel faktör üzerine odaklanmaları gerekmektedir (Bamberger, Bettati, Hoeffinger, Kuruvilla ve Wille, 2009:7):

1. Yolcu başı satın alma harcamaları arttırılmalıdır: Yolcuların daha fazla harcamada bulunması için havalimanlarının perakende alanlarını arttırmasını önermektedir. Yolcu harcamalarının parfüm ve kozmetik türü ürünlerde en fazla artış göstereceği, sonrasında pastaşekerleme ve sağlıklı gıda ürünlerinde olacağını, üçüncü sırada ise gümrüksüz mağazacılığın yer alacağını belirtmektedir. Parfüm ve kozmetik grubunun az yer kaplayıp daha karlı olmasının avantajlı olacağını vurgulamaktadır.

2. Havalimanının yolcu profilinin belirlenip, sunulan ürünlerin uyarlanması gerekmektedir: Özellikle tatil ve iş amaçlı seyahat eden yolcuların profil özelliklerine göre mağaza ve ürün çeşitliliğine dikkat edilmesini önermektedir.

3. Göz atan yolcuları satın alanlara dönüştürülmesi sağlanmalıdır: Havalimanı tasarımının da katkısıyla son güvenlik noktasından hemen sonra planlanmış ürünleri satın almaları için firsat yaratıp, kapı (gate) bölgesine kadarki yürüyüş alanlarını mağazaların içerisine dahil edecek şekilde yönlendirip yolcuların göz atmasını sağlayarak son dakika kampanyaları ile ekstra satın almada bulunmaya teşvik edilmesi önerilmektedir. Stockholm Arlanda Havalimanı'nı Terminal 5'te yapılan bu uygulama ile yolcuların \%60'1 kapı (gate) bölgesine ulaşıncaya kadar $1.700 \mathrm{~m} 2$ 'lik mağaza alanından geçmek durumundadırlar.

4. Şehir merkezindeki perakendecilerden daha avantajlı fiyatlar sunmaya çalışılmalıdır.

5. Havalimanını gezmeye gelen kişiler, havalimanında çalışan personel, yolcu karşılamaya gelen kişileri de hedef alacak şekilde havalimanında bulunan diğer kişileri de potansiyel alıcı olarak görülmeye başlanmalıdır. 
Bir diğer bakış açısına göre havalimanı perakendecilerinin dikkat etmesi gereken 5 temel nokta aşağıdaki gibi önerilmektedir (Duffy C.Weir, http://specialtyretail.com/issue/2013/04/retailinglocations/reaching-for-the-sky/):

- Mekân ve Operasyonel Farklılıkların Keşfedilmesi: 365 gün 7 / 24 faaliyet gösteren mağazalar olması ve genelde kiraların alışveriş merkezlerine göre daha fazla olduğu, genellikle garanti kira + satışlardan belirli bir yüzde şeklinde olması hissesi olmayan ortak şeklinde karşınıza çıkabilmektedir. Ürün çeşitliliğinde marka bilinilirliğine ve de pratik taşınabilirliğine dikkat edilmesi gerekmektedir.

- Güvenlik Prosedürlerinin İyi Anlaşılması: Tüm çalışanlar için havalimanı girişi için yaka kartlarının çıkartılması ve kullanılması çok önemli bir ayrıntıdır. Kart sahibi personelin uygunsuz davranışlarından çalıştığı firma yetkilisi sorumlu tutulmaktadır (DHMİ, Tüm Havaalanları Giriş Kartı Talimatı (SHT - 17.1) Madde 8/f).

- Daha Küçük Bir Alanda Perakendecilik Yapılması: Baltimore - Washington Thurgood Marshall Havalimanı (BWI) havalimanı genel müdür yardımcısı Brett Kelly'e göre, havalimanı perakendeciliğinde, geleneksel perakendeciliğe göre en çok dikkat edilmesi gereken nokta sınırlı mağaza alanının verimli kullanılabilmesidir (Duffy C. Weir, http://specialtyretail.com/issue/2013/04/retailing-locations/reaching-for-the-sky/,). Keza normal şartlardaki bir mağazaya göre havalimanında aynı ürün dizisinin (hattının) (merchandising) yaklaşık \%20'si kadar alana sığdırmayı gerektirmektedir. Bunun için de müşteri profiline en uygun ürünleri tercih etmek gerekmektedir.

- İş Süreçlerinde Sabırlı Olunması: Havalimanında iş yeri açabilme süreçleri devlet otoritesinin kontrol ve denetiminde yürütüldüğü için uzun zaman alabilir ve bürokratik süreç uzayabilir. Ayrıca mağaza kiralama ve açma hazırlıkları da geleneksel süreçlerden uzun zaman alabilecektir.

- Kuruluş Maliyetlerine Dikkat Edilmesi: Geleneksel perakendeciliğe göre maliyetler iki kata yükselebilir. Mağaza tasarımı ve mağazada kullanılan malzemeler birinci sınıf olmalıdır. Havalimanlarının sahip olduğu yeşil havalimanı (green airport: çevre dostu havalimanı), engelsiz havalimanı (barrier - free airport: engelli yolcuların kullanımına uygun havalimanı) gibi sertifikalar uygun tasarımlar yapılmalı bu da ekstra maliyet yaratmaktadır.

\section{Sonuç}

Havalimanı ve terminallerinde gümrük, emniyet, özel güvenlik, yer hizmetleri, havayolu şirketleri gibi birçok işletmenin personelleri çalışmakta olup görevleri gereği yolcular ile etkileşim halindedirler. Söz konusu personellerin tamamının; iletişim, hizmet kalitesi, müş̧eri memnuniyeti gibi konularda düzenli olarak eğitime alınmasında yarar vardır. Çünkü ortalama bir yolcunun temas kurduğu personelin hangi kuruma bağlı olduğunu bilmesi mümkün olmamakta, hangi kurum personeli olduğunu ayırt edebilse bile, memnuniyetsizlik yaşadığı durumlarda ayrım yapmaksızın terminal işletmecisinin personeli olduğuna dair kanıya kapılıp memnuniyetsizlik kaynağı olarak terminal işletmecisini sorunlu tutabileceklerdir. Bu bağlamda öncelikle personele yönelik eğitim faaliyetlerine ağırlık verilmelidir.

Buradan hareketle, memnuniyetsizlik sebepleri tespit edilerek yolcuların satın alma ihtimallerini arttırıcı önlemler alınabilecektir. Yolcuların en hızlı şekilde terminalin hava tarafina alınması önem arz etmektedir. Bu sebeple yolcuların terminale girişte karşılaştığı özel güvenlik personeli, check-in işlemlerini gerçekleştiren yer hizmeti kuruluşunun personeli, pasaport kontrolünü gerçekleştiren polisin de bu sürece katkısı göz önünde bulundurulmalıdır. Hızlı bir şekilde uçuşa biniş (boarding) aşamasına gelen yolcu üzerinde geç kalma baskısı azalacak ve satın almada bulunmak için zamana ihtiyacı olacaktır. $\mathrm{Bu}$ da perakendecilik gelirlerinin artmasına olanak sağlayabilecektir. Aynı zamanda Türkiye'nin uluslararası uçuşlarda aktarma merkezi olma yolunda 
gelişen havalimanlarına sahip olması, transit yolcuların da artmasına sebep olmuştur. Transit yolcular da perakendeci işletmeler için önemli gelir kaynakları arasında yer almaktadır. Transit yolculara yönelik perakendecilik uygulamalarının geliştirilmesinde yarar görülmektedir.

Özellikle turistik amaçlı seyahat eden yolcularda, seyahat ettiği ülkeye tekrar ziyaret zamanının belirsiz olması ya da uzun bir süre sonra olacak olması, yolcularda hediye / hatıra amaçlı ürün satın alma duygusunu arttırabilmektedir. Ayrıca, turistlerin ceplerinde kalan o ülkeye ait yerel parayı kendi ülkelerinde kullanamama ihtimali de harcama eğilimi oluşturabilmektedir. Bu bağlamda perakende noktalarında cepte kalan son paraları harcayabilmeleri için düşük fiyatlı, hediye edilebilecek, hatıra özelliği bulunabilecek ürün çeşitliliğinin artırılmasında fayda görülmektedir. Havalimanını kullanan yolcu profilinin satın alma davranışları araştırılarak, en sık rastlanan yolcu tipolojisine göre ürün çeşitliliği de sağlanmalıdır. Çin'de ortaya çıkıp dünyayı etkisi altına alan COVID - 19 pandemisinin olumsuz etkilediği sektörlerin başında havacılık sektörü gelmektedir. Havayolları ve havalimanları pandemi sonrası için yeni önlemler geliştirmek zorundadırlar. $\mathrm{Bu}$ kapsamda kabin ekiplerinin ve de yolcuların seyahatleri sırasında ihtiyaç duyabilecekleri kişisel temizlik, dezenfektan, maske, parfüm gibi ürünlerin de çeşitlendirilmesinde yarar vardır.

Terminaldeki mağaza lokasyonlarının, yolcuların pasaport kontrolden uçağa bininceye kadar yürüdükleri alan üzerinde bulunmasının sağlanmasına ve kapı (gate) bölgelerinden kolaylıkla görsel erişimin sağlanabileceği şekilde konumlanmasında fayda görülmektedir. Terminale yolcu karşılamaya, yolcu göndermeye gelenler ile havalimanı çalışanlarının da potansiyel müşteri olduğu göz ardı edilmeyip onlara da ürün-hizmet satmak için çaba harcanmalıdır.

\section{Kaynakça}

Appold, S. J. ve Kasarda, J. D. (2006). "The appropriate scale of US airport retail activities.” Journal of Air Transport Management, 12(6): 277-287.

A\&T Bank (2019). Perakende Sektörü Raporu.

https://www.atbank.com.tr/documents/PERAKENDE\%20SEKTORU_MART\%202019.PDF

BAA (2018). Heathrow Airport Report.

https://www.heathrow.com/file_source/Heathrow/Static/PDF/Heathrow-SP-Limited-Q4-2018results-release.pdf

Bamberger, V., Bettati, A., Hoeffinger, S., Kuruvilla T. ve Wille V. (2009). Mastering Airport Retail: Roadmap to New Industry Standarts, Arthur D Little Research.

Baron, S. ve Wass, K. (1996). "Towards an understanding of airport shopping behaviour. international review of retail." Distribution and Consumer Research, 6(3): 301-322.

Benham, D. (2009). "Successfully optimising retail space from existing airport facilities." Journal of Airport Management, 4(1): 8-13.

Crawford, G. ve Melewar, T. C. (2003). "The importance of impulse purchasing behaviour in the international airport environment." Journal of Consumer Behaviour, 3(1): 85-98.

DHMI, Tüm Havaalanları Giriş Kartı Talimatı (SHT - 17.1) Madde 8/f).

Doganis, R. (1992). The Airport Business. London; New York: Routledge.

Duval, D. (2007). Tourism and Transport: Modes, Networks and Flows. Buffalo: Channel View Publications. 
Entwistle, M. (2007). "Customer service and airport retail: Stimulate passenger spending." Journal of Airport Management, 1(2): 151-157.

Freathy, D. P. ve O'Connell, F. (1998). European Airport Retailing: Growth Strategies for the New Millennium. Basingstoke: Palgrave Macmillan.

Freathy, P. ve O’Connell, F. (1999). “A typology of European airport retailing.” Service Industries Journal, 19(3): 119-134.

Freathy, P. ve O'Connell, F. (2012). "Spending time, spending money: Passenger segmentation in an international airport." The International Review of Retail, Distribution and Consumer Research, 22(4): 397-416.

Geuens, M., Vantomme, D. ve Brengman, M. (2004). "Developing a typology of airport shoppers." Tourism Management, 25(5): 615-622.

Gkritza, K., Niemeier, D. ve Mannering, F. (2006). "Airport Security Screening and Changing Passenger Satisfaction: An Exploratory Assessment." Journal of Air Transport Management, 12(5), 213-219.

GlobalData (2016). Global Airport Retailing Report:2017-2022

Graham, A. (2008). Managing Airports: An International Perspective (third edition.). Oxford; Burlington, MA: Routledge.

Graham, A. (2009). "How important are commercial revenues to today's airports?" Journal of Air Transport Management, (3):106-111.

Hobson, J. P. (2000). “Tourist shopping in transit: The case of BAA.” Journal of Vacation Marketing, 6(2): 170-183.

Hsu, C.-I. ve Chao, C.-C. (2005). "Space allocation for commercial activities at international passenger terminals." Transportation Research Part E: Logistics and Transportation Review, 41(1): 29-51.

Huang, W.-H. ve Kuai, L. (2006). "The in-flight shopper." Journal of Air Transport Management, 12(4): 207-211.

IATA, (2017), Press Release No: 55, https://www.iata.org/en/pressroom/pr/2017-10-24-01/

Jarach, D. (2001). "The evolution of airport management practices: Towards a multi-point, multiservice, marketing-driven firm." Journal of Air Transport Management, 7(2): 119-125.

Jarach, D. (2005). Airport Marketing: Strategies to Cope with the New Millennium Environment. Aldershot, Hampshire, England; Burlington, VT: Avebury Aviation.

Keown, C. F. (1989). "A model of tourists' propensity to buy: The case of Japanese visitors to Hawaii." Journal of Travel Research, 27(3): 31-34.

Kim, H. ve Shin, J.-H. (2001). "A contextual investigation of the operation and management of airport concessions.” Tourism Management, 22(2): 149-155.

Knight, M. R. (2009). “Taking flight: Airport shopping and dining.” Research Review, 16(1): 37-40.

KPMG (2019). Sekteröl Bakıs - Perakende Raporu. https://assets.kpmg/content/dam/kpmg/tr/pdf/2019/03/sektorel-bakis-2019-perakende.pdf

Laesser, C. ve Dolnicar, S. (2012). "Impulse purchasing in tourism-learnings from a study in a matured market." Anatolia: An International Journal of Tourism and Hospitality Research, 23(2): 268-286. 
Lee, J. A. ve Kacen, J. J. (2008). "Cultural influences on consumer satisfaction with impulse and planned purchase decisions." Journal of Business Research, 61(3): 265-272.

Perng, S.-W., Chow, C.-C. ve Liao, W.-C. (2010). "Analysis of shopping preference and satisfaction with airport retailing products." Journal of Air Transport Management, 16(5): 279-283.

Scholvinck, J., 2000. The Travel Stress Curve. Market Square Consulting, Amsterdam

SHGM (2019), Sivil Havacılık Genel Müdürlüğ̈̈ 2018 Faaliyet Raporu, http://web.shgm.gov.tr/documents/sivilhavacilik/files/pdf/kurumsal/faaliyet/2018.pdf

Stasiulevicuis, G. (2012). "Revealing shopper truths in travel retail." Journal of Airport Management, 6(3): 217-224.

Thompson, B. (2007). "Airport retailing in the UK." Journal of Retail \& Leisure Property, 6(3): 203-211.

Timothy, D. J. (2005). Shopping Tourism,Retailing and Leisure. Clevedon, UK; Buffalo, NY: Channel View Publications.

Topping, P. (2010). "Promotions and incentives in airport retailing." Journal of Airport Management, 4(3): 208-210.

Torres, E., Dominguez, J. S., Valdes, L. ve Aza, R. (2005). "Passenger waiting time in an airport and expenditure carried out in the commercial area." Journal of Air Transport Management, 11(6): 363-367.

Tovar, B. ve Martín-Cejas, R. R. (2009). “Are outsourcing and non-aeronautical revenues important drivers in the efficiency of spanish airports?" Journal of Air Transport Management, 15(5): 217-220.

Zhang, A. ve Zhang, Y. (1997). "Concession revenue and optimal airport pricing." Transportation Research Part E: Logistics and Transportation Review, 33(4): 287-296.

Duffy C. Weir, Consultant in the Retail Marketing,http://specialtyretail.com/issue/2013/04/retailing-locations/reaching-for-thesky/.

Juliet Mann, http://edition.cnn.com/2012/03/08/business/mpe-ryanair ceo/index.html

World's Best Airport Shopping 2019, https://www.worldairportawards.com/worlds-best-airportshopping-2019/

http://web.shgm.gov.tr/documents/sivilhavacilik/files/pdf/kurumsal/faaliyet/2018.pdf,

http://www.havayolu101.com/2011/08/10/markalar-havalimanini-yeniden-kesfediyor/

http://www.havayolu101.com/2012/08/17/alti-farkli-havalimani-musterisi

http://www.airporthaber.com/havacilik-haberleri/duty-free-taktikleri.html

http://www.passengerselfservice.com/2013/05/10/frankfurt-airport-fra-is-testing-a-qr-wall-forshopping

http://www.airparks.co.uk/gatwick-airport-shopping.html

http://www.airparks.co.uk/gatwick-airport-shopping.html

http://www.retail-week.com/sectors/food/in-pictures-tesco-launches-virtual-shopping-wall-atgatwick-airport/5039449.article 
http://www.airporthaber.com/havacilik-haberleri/duty-free-taktikleri.html http://www.netnuancedf.com/index.php?tarihce=1

http://www.airporthaber.com/havacilik-haberleri/eglenceye-ucuyoruz.html

http://www.airporthaber.com/havacilik-haberleri/duty-free-taktikleri.html

https://www.skyscanner.com.tr/haberler/ziyaret-etmeniz-gereken-11-ultra-modern-havaalani

https://www.igairport.com/tr/basin-bultenleri/dunyanin-en-buyuk-duty-free-anlasmasi-imzalandi

https://www.igairport.com/tr/basin-bultenleri/iga-ceosu-kadri-samsunlu-istanbul-havalimaninibbcye-anlatti

https://ticaret.gov.tr/data/5d63d89d13b8762f7c43a738/32-

gumruksuz\%20Satis\%20Magazasi\%20Sayilari.pdf

https://www.dhmi.gov.tr/sayfalar/istatistik.aspx 